\title{
Compliance with screening for and recommended management of maternal group B streptococcus carriage in pregnancy
}

\section{Authors}

Rebecca MOORHEAD ${ }^{1}$, Andrew J DALEY ${ }^{2,3,4}$, Lai-yang LEE ${ }^{2,3}$, Alexandra GORELIK ${ }^{5}$, Suzanne M. GARLAND $2,3,5,6$.

1. Faculty of Medicine, University of Melbourne, Parkville, Australia

2. Department of Microbiology and Infectious Disease, Royal Women's Hospital, Parkville, Australia

3. Department of Microbiology, Royal Children's Hospital, Parkville, Australia

4. Department of Paediatrics, University of Melbourne, Parkville, Australia

5. Melbourne EpiCentre, Royal Melbourne Hospital, Parkville, Australia

6. Department of Obstetrics and Gynaecology, University of Melbourne, Victoria, Australia

7. Infection and immunity, Murdoch Children's Research Institute, Parkville

\begin{tabular}{|c|c|c|}
\hline Y & Position & Institutional Affiliation \\
\hline $\begin{array}{l}\text { Rebecca A MOORHEAD } \\
\text { rebecca.a.moorhead@gmail.com } \\
\text { rebecca.moorhead2@mh.org.au }\end{array}$ & MD & $\begin{array}{l}\text { Faculty of Medicine, University of Melbourne, } \\
\text { Parkville, Australia }\end{array}$ \\
\hline $\begin{array}{l}\text { Andrew J DALEY } \\
\text { andrew.daley@rch.org.au }\end{array}$ & Associate Professor & $\begin{array}{l}\text { Department of Microbiology and Infectious } \\
\text { Disease, Royal Women's Hospital, Parkville, } \\
\text { Australia } \\
\text { Department of Microbiology, Royal Children's } \\
\text { Hospital, Parkville, Australia } \\
\text { Department of Paediatrics, University of } \\
\text { Melbourne, Parkville, Australia }\end{array}$ \\
\hline $\begin{array}{l}\text { Lai-Yang LEE } \\
\text { Lai-Yang.Lee@rch.org.au }\end{array}$ & MD & $\begin{array}{l}\text { Department of Microbiology and Infectious } \\
\text { Disease, Royal Women's Hospital, Parkville, } \\
\text { Australia } \\
\text { Department of Microbiology, Royal Children's } \\
\text { Hospital, Parkville, Australia }\end{array}$ \\
\hline $\begin{array}{l}\text { Alexandra GORELIK } \\
\text { alexandra.gorelik@gmail.com }\end{array}$ & Senior statistician & $\begin{array}{l}\text { Melbourne EpiCentre, Royal Melbourne } \\
\text { Hospital, Parkville, Australia }\end{array}$ \\
\hline $\begin{array}{l}\text { Suzanne M GARLAND } \\
\text { Suzanne.Garland@thewomens.org.au }\end{array}$ & Professor & $\begin{array}{l}\text { Department of Microbiology and Infectious } \\
\text { Disease, Royal Women's Hospital, Parkville, }\end{array}$ \\
\hline
\end{tabular}

This is the author manuscript accepted for publication and has undergone full peer review but has not been through the copyediting, typesetting, pagination and proofreading process, which may lead to differences between this version and the Version of Record. Please cite this article as doi: $\underline{10.1111 / \mathrm{AJO} 0.12977}$

This article is protected by copyright. All rights reserved 


\begin{tabular}{|l|l|}
\hline & Australia \\
& Department of Microbiology, Royal Children's \\
& Hospital, Parkville, Australia \\
& Department of Obstetrics and Gynaecology, \\
& University of Melbourne, Victoria, Australia \\
& Infection and immunity, Murdoch Children's \\
& Research Institute, Parkville \\
\hline
\end{tabular}

\section{Corresponding Author}

Dr. Rebecca Moorhead BSci MD

rebecca.a.moorhead@gmail.com

7 Dorrington Avenue, Glen Iris, Victoria 3146

\section{Acknowledgements}

Staff at The Royal Women's Hospital Health Record Information Services, Quality and Safety Unit, Department of Women's Research, Department of Obstetrics and the Royal Children's Hospital Pathology Collection and Laboratory Services.

RAM has no conflicts to declare with respect to the topic of this work.

AJD has no conflicts of interest to declare.

LYL has no conflicts of interest to declare with respect to this work.

AG has no conflicts of interest to declare.

SMG has no conflicts to declare with respect to the topic of this work.

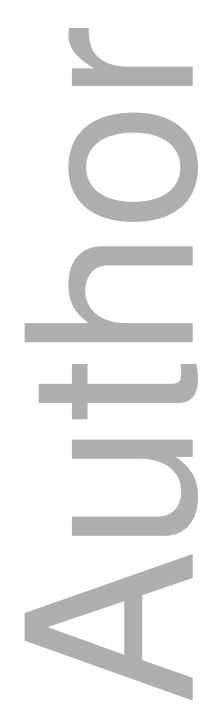


Article type : Original Manuscript

Title: Compliance with screening for and recommended management of maternal group B streptococcus carriage in pregnancy

Short Title: Compliance with screening for GBS in pregnancy

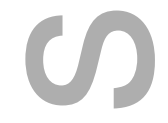

Main text word count: 1951

Abstract word count: 233

Figure count: 1

Table count: 4

Key Words: Group B Streptococcus, pregnancy, screening, compliance, prophylaxis

\section{Abstract}

Background

Universal screening of pregnant women at 35-37 weeks' gestation is recommended for detection of anogenital group B streptococcus carriage. Intrapartum chemoprophylaxis is prescribed to carriers to prevent transmission to babies, reducing early-onset neonatal group B streptococcal sepsis.

Aims

To review compliance with, and the effects of education on group B streptococcus screening and intrapartum chemoprophylaxis practices at The Royal Women's Hospital, Melbourne, Australia. Materials \& Methods

A retrospective audit of women delivering in February 2016 and February - March 2017 was conducted. In February 2017, updated early onset group B streptococcal disease prevention guidelines were released and promoted with targeted education of clinical staff. Compliance was considered appropriate if practices followed up-to-date local protocols.

Results

Screening rate for group B streptococcus was 84.4\% (599/710) and carriage rate 19.5\% (109/558), whilst intrapartum antibiotic prophylaxis was optimal in $83 \%$ of those labouring greater than four hours This article is protected by copyright. All rights reserved 
(39/47). There was no significant difference in compliance between 2016 and 2017. Of 113 women with unknown group B streptococcal status at delivery, only 5 of $33(15 \%)$ with clinical risk factors for early onset neonatal disease received intrapartum prophylaxis.

\section{Conclusions}

Compliance remained stable, with no change during or after implementation of new protocols. Compliance with protocols was low for cases with unknown group B streptococcal status at delivery but with the presence of one or more clinical risk factors for early onset group B streptococcal sepsis.

\section{Introduction}

Group B streptococcus (GBS) or Streptococcus agalactiae is a Gram-positive bacterium carried asymptomatically in the genital and gastro-intestinal tracts in $15-25 \%$ of women of childbearing age. ${ }^{1}$ Transmission of GBS to the infant during birth, resulting in colonisation, occurs in $50-70 \%$ of GBS carrier mothers. Contemporary rates show an estimated 1-2\% of infants born to colonised mothers who have not developed antibodies to the GBS serotype that they carry, will develop early-onset GBS (EOGBS) infection, unless intrapartum transmission is interrupted by appropriate antibiotic prophylaxis. Contemporary fatality rates for EOGBS range from $4-20 \%{ }^{1}$

Significant reductions in EOGBS disease have followed widespread adoption of intrapartum antibiotic prophylaxis (IAP) of earrier mothers after it emerged as an effective strategy in the $1980 \mathrm{ss}^{2}$ In the late 1990s, The Centers for Disease Control and Prevention (CDC) in the United States recommended two strategies for identifying women who should receive IAP: a risk-based approach and a culture-based screening approach. ${ }^{3}$ The former involves recognition of maternal risk factors during labour, whilst the latter involves screening all pregnant women by taking anorectal and vaginal swabs for detection of GBS colonisation. Over the past 20 years, the guidelines have been revised. The CDC and The Royal Australian and New Zealand College of Obstetricians and Gynaecologists (RANZCOG) currently recommends universal culture-based screening for identifying mothers who will benefit from IAP. ${ }^{4,5}$ Based on outcomes from earlier prevention strategies the RWH has adopted universal screening of all pregnant women and IAP to reduce colonisation and EOGBS sepsis in their babies. ${ }^{2,6-8}$ Ideally, pregnant women are screened at 35-37 weeks' gestation, and those who are GBS positive receive intravenous intrapartum penicillin, or alternate antibiotics (clindamycin or vancomycin depending on sensitivities). ${ }^{5}$ GBS susceptibility testing is not routinely performed on screening swabs unless specifically requested.

Optimal neonatal outcome requires compliance with screening guidelines and attention to implementation and maintenance of protocols. ${ }^{9}$ Although rates of compliance up to $80 \%$ have been noted, ${ }^{10}$; there is variability in opinions between Obstetricians regarding maternal screening and This article is protected by copyright. All rights reserved 
chemoprophylaxis for GBS and a considerable proportion do not follow the practice guidelines developed by the CDC, such as performing vaginal, without anal swabs. ${ }^{11}$ Confirmed cases of EOGBS sepsis, despite implementation of screening and IAP, have been attributed to non-compliance with screening protocols, but there is limited evaluation of this in the literature. ${ }^{12}$ The CDC encourages local hospitals to establish surveillance for EOGBS disease and take other steps to promote perinatal GBS disease prevention and education in order to reduce local incidence. ${ }^{1}$ Ownership of and responsibility for protocols, staff education and periodic evaluation of compliance with feedback are amongst the strategies identified to improve and maintain high levels of compliance. ${ }^{9}$ This research aims to review the effect of doctor and midwife education on, and overall compliance with screening for GBS carriage during pregnancy and IAP for GBS carriers at RWH.

\section{Materials \& Methods}

A retrospective audit of women who delivered at RWH during the months of February 2016, February 2017 and March 2017 was conducted. In February 2017, updated EOGBS prevention guidelines (Figure 1) were released, promoted and clinical staff were educated. ${ }^{13}$ Pathology request forms were updated to include documentation of GBS swab collection site, collector and presence of penicillin allergy. Evidence of antenatal GBS screening and appropriate IAP was obtained from a total of 741 medical records in addition to birth-centre databases and the Laboratory Information System. Compliance with screening and IAP was considered appropriate if practices followed up-to-date local protocols. ${ }^{7,13}$ Maternal risk factors for EOGBS disease included maternal fever during labour greater than $38^{\circ} \mathrm{C}$, rupture of membranes of greater than 18 hours, premature delivery at less than 37 weeks' gestation and an infant previously affected by GBS. All data analysis was performed using Microsoft Excel and SPSS.

All data was collected with permission granted by The Human Research and Ethics Committees at The Royal Women's Hospital (Project AQA 17/10).

\section{Results}

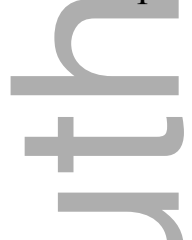

Women who delivered $\geq 35$ weeks were deemed eligible for screening, as were those $>37$ weeks' gestation. A summary of the audit results is presented in Table 1. Of 558 women who were screened, $19.5 \%$ (109/558) were carriers of GBS. Compliance with IAP practices in women who experienced labour (i.e. did not have a planned or unplanned caesarean section without labour) is presented in Table 2. Compliance in terms of antibiotic choice and dose was $99 \%$ (93/94). However, compliance was $83 \%$ (39/47) when taking into account timing of the first dose, as IAP must be administered at least 4 hours 
prior to delivery. There was no significant difference in compliance between 2016 and 2017 (p >0.05) nor was there any fall in compliance with the implementation of new protocols in February 2017. The intervention lead to significant improvement in documentation of swab site (vaginal, rectal or both) from $2 \%(4 / 201)$ to $70.4 \%(138 / 196, \mathrm{p}<0.001)$ and swab collector (self, midwife or doctor) from $63.2 \%(127 / 201)$ to $95.4 \%(187 / 196) \mathrm{p}<0.001)$. Of note, none of the four women who had documented swabs sites in February 2016 had combined anorectal plus vaginal swabs, however this rose significantly in March 2017 to $90.6 \%$ (125/138, p<0.001).

Of the 113 women with unknown GBS status at delivery, only 5 of $33(15 \%)$ with clinical risk factors for EOGBS disease received IAP, as summarised in Table 3. There were no cases of EOGBS disease across the study period.

A total of $7.0 \%(52 / 741)$ of women audited reported an allergy to penicillin. Specifically, $15 \%(8 / 52)$ reported an immediate hypersensitivity such as anaphylaxis; 69\% (36/52) reported nausea, vomiting or rash and a further $15 \%(8 / 52)$ had unspecified allergies. Of these women, 15\% (8/52) were eligible for and received IAP and 5 of these 8 received appropriate antibiotic coverage given their allergy.

\section{Discussion}

The purpose of this study was to observe practice and compliance with obstetric GBS management guidelines. Swab culture results representative of GBS status at delivery taken from 1-5 weeks before delivery have high sensitivity and specificity, but decline when greater than 6 weeks has elapsed between culture and birth of the baby. ${ }^{16}$ Compliance with screening was high, with $84.4 \%$ (599/710) of eligible women (who gave birth at greater than 35 weeks' gestation) undergoing GBS screening. The intestinal tract is recognised as an important reservoir for GBS and combined vaginal-anorectal swabs for culture have been shown to significantly improve GBS detection rates compared to single vaginal or anorectal cultures. ${ }^{16,17}$ Self-collected swabs taken by the patient compared with those taken by a healthcare provider have similar GBS detection rates. ${ }^{17}$ In the current study, pathology request forms were updated with tick boxes to indicate swab site, collector and history of penicillin allergy. There was improvement of documentation; $90.6 \%$ (125/138) of documented swabs were taken as a combined vaginal-anorectal site and $81.8 \%$ (153/187) were self-collected by the patient. This provides reassuring evidence of compliance with guidelines, patient involvement and also confidence in our GBS culture yields.

The carriage rate for GBS of $19.5 \%$ (109/558) was within the expected range. ${ }^{1,9,10}$ Women who experienced labour and met primary risk factors for EOGBS were included (maternal colonisation, evidenced by a positive GBS screening swab at >35 weeks or GBS bacteriuria at any gestational age) and $92.2 \%(94 / 102)$ were prescribed IAP. ${ }^{1,17}$ With very few exceptions, GBS remains fully susceptible to penicillin. ${ }^{1,5,13}$ Adequate prophylaxis is considered to be administration of at least one dose of intravenous benzyl-penicillin greater than four hours before delivery ${ }^{18}$ Appropriate compliance in terms This article is protected by copyright. All rights reserved 
of antibiotic choice, dose and timing was 83\% (39/47). In previous studies, indicators of compliance were often unclear ${ }^{9,10}$ For example, in one study, women who arrived at the birth suite 30 minutes or less before delivery were excluded and no details were given in regards to choice or dose of antibiotic. 10 To ensure an accurate compliance rate in this current study, women who gave birth before 35 weeks' gestation or were screened prior to 35 weeks' gestation, those who did not experience labour (i.e. had a planned or unplanned caesarean section with no labour) and those who experienced a labour of less than four hours were excluded. Compliance remained stable across the study period, with no change during or after the implementation of education and new protocols and was comparable to that of previous publications. Compliance failure was primarily due to antibiotic administration timing. Additional risk factors for EOGBS sepsis to those mentioned above include: spontaneous onset of labour at less than 37 weeks' gestation, rupture of membranes greater than 18 hours, maternal fever greater than $38^{\circ} \mathrm{C}$, a previous infant with EOGBS, and a clinical diagnosis of chorioamnionitis in the mother. ${ }^{5,9}$ In women who have unknown GBS status at delivery, the presence of 1 or more of these risk factors should be used as an indication for IAP. ${ }^{19}$ In this study, compliance with risk based assessment protocols was low, with only 5 of 33 women (15\%) receiving antibiotics before labour. In this study, appropriate antibiotic choice given documented allergy in women who received IAP was sub-optimal. A total of $7 \%$ of women (52 of 741) reported an allergy to penicillin, with 15\% (8/52) giving a history of anaphylaxis. Allergy definition and documentation was poor and this was likely an overestimate of women with true anaphylactic/ anaphylactoid reactions. It is imperative that allergy is accurately documented and GBS susceptibility testing is specifically requested at the time of GBS culture, as there have been concerns of rising rates of resistance to alternative choices, in particular clindamycin. $^{7} 20$

Labour was diagnosed according to The Royal Women's Hospital guidelines (the time between the recorded commencement of labour and delivery of the baby). ${ }^{21}$ Many women were given IAP before labour had been confirmed and recorded in the Birth Centre database. Whilst the screening approach is effective when IAP is administered correctly, the population of women who laboured for a length of time long enough for 'adequate' IAP was limited. Appropriate documentation of labour and timing of antibiotic administration would provide more accurate data for future audits.

Universal screening and administration of IAP is a resource-intensive intervention and the implementation to the high proportion of worldwide deliveries outside of healthcare institutions, particularly in low-income countries, is challenging. ${ }^{23}$ Concerns have also been raised regarding the large number of mothers who receive antibiotics, including the potential hazards to recipients and emerging penicillin resistant GBS strains. There are reports of isolates with increasing minimum inhibitory concentrations (MICs) to penicillin, but the clinical significance of these isolates remains unclear. On-going monitoring of GBS isolates is thus paramount. ${ }^{24,25}$ Penicillin administered to a woman with no known history of a $\beta$-lactam allergy carries an extremely low risk of anaphylaxis and This article is protected by copyright. All rights reserved 
mortality in the hospital setting is rare. It is crucial that clinical staff elicit an appropriate history and document the exact nature of any allergies, as is true for all areas of clinical medicine. Ultimately, vaccination against GBS would increase the proportion of women and babies able to be protected from GBS disease, without the implications of antibiotic overuse, penicillin allergy or compliance failure. Until such a vaccine is available, universal screening and intrapartum chemoprophylaxis in accordance with guidelines remains an important part of antenatal care.

This study represents the first audit of compliance for GBS screening and IAP at this hospital and will inform and improve clinical practice and neonatal outcomes. A list of practical recommendations can be found in Table 4. Targeted education, combined with audits and feedback, can increase rates of routine testing successfully in an outpatient setting and can be used to improve implementation and compliance with new guidelines. ${ }^{25}$ To further improve compliance, the results of this audit were provided to clinical staff in September 2017. Future audits are planned to identify further areas for improvement.

\section{References}

1. Verani, J.R., McGee, L, Schrag, S.J. Prevention of Perinatal Group B Streptococcal Disease revised guidelines from the CDC. MMWR Recomm Rep 2010; 59(45): 1-32.

2. Garland, S.M., Fliegner, J.R. Group B streptococcus (GBS) and neonatal infections: the case for intrapartum chemoprophylaxis. Aust N Z J Obstet Gynaecol 1991; 31(2): 119-22.

3. Centers for Disease Control and Prevention. Prevention of Perinatal Group B Streptococcal Disease: A Public Health Perspective. MMWR Recomm Rep 1996; 45(RR-7): 1-24.

4. Centers for Disease Control and Prevention. Guidelines for the prevention of perinatal group B streptococcal disease. [Accessed May 2017] Available from URL: http://www cdc gov/groupbstrep/guidelines/guidelines html; 2010.

5. The Royal Australian and New Zealand College of Obstetricians and Gynaecologists. Maternal Group B Streptococcus in pregnancy: screening and management (C-Obs 19). [Accessed May 2017]. Available from: https://www.ranzcog.edu.au/Statements-Guidelines/; 2016.

6. Garland, S.M. Early onset neonatal group B streptococcus (GBS) infection: associated obstetric risk factors. Aust N Z J Obstet Gynaecol 1991; 31(2): 117-8.

7. The Royal Women's Hospital. GBS Colonisation: Antenatal/Intrapartum Strategies to Prevent Early-Onset Neonatal Sepsis. [Accessed May 2017]. Available from: https://www.thewomens.org.au/health-professionals/clinical-resources/clinical-guidelines-gps/; 2015. 8. The Royal Women's Hospital. GBS Colonisation: Management of Infant to Prevent Early Onset Group B Streptococcus (EOGBS) Disease. [Accessed May 2017]. Available from: https://www.thewomens.org.au/health-professionals/clinical-resources/clinical-guidelines-gps/; 2015. This article is protected by copyright. All rights reserved 
9. Gilbert, G.L., Hewitt, M.C., Turner, C.M., Leeder, S.R. Compliance with protocols for prevention of neonatal group B streptococcal sepsis: practicalities and limitations. Infect Dis Obstet Gynaecol 2003; 11(1): 1-9.

10. Cheon-Lee, E., Amstey, M.S. Compliance with the Centers for Disease Control and Prevention antenatal culture protocol for preventing group B streptococcal neonatal sepsis. Am J Obstet Gynaecol 1998; 179(1): 77-9.

11. Mahieu, L.M., De Dooy, J.J., Leys, E. Obstetricians' compliance with CDC guidelines on maternal screening and intrapartum prophylaxis for group B streptococcus. J Obstet Gynaecol 2000; 20(5): 460-4.

12. Jeffery, H.E., Moses Lahra, M. Eight-year outcome of universal screening and intrapartum antibiotics for maternal group B streptococcal carriers. Pediatrics 1998; 101(1): E2-E.

13. The Royal Women's Hospital. GBS Colonisation: Antenatal/Intrapartum Strategies to Prevent Early-Onset Neonatal Sepsis. [Accessed May 2017]. Available from:

https://www.thewomens.org.au/health-professionals/clinical-resources/clinical-guidelines-gps/; 2017.

14. Dillon, H.C., Gray, E, Pass, M.A., Gray, B.M. Anorectal and Vaginal Carriage of Group B Streptococci during Pregnancy. J Infect Dis 1982; 145(6): 794-9.

15. Kovavisarach, E., Sa-adying W., Kanjanahareutai S. Comparison of combined vaginalanorectal, vaginal and anorectal cultures in detecting of group B streptococci in pregnant women in labor. J Med Assoc Thai 2007; 90(9):1710-4.

16. Arya, A., Cryan, B., O'Sullivan, K., et al. Self-collected versus health professional-collected genital swabs to identify the prevalence of group B streptococcus: a comparison of patient preference and efficacy. Eur J Obstet Gynaecol Reprod Biol 2008; 139(1): 43-5.

17. Persson, K., Bjerre, B., Elfström, L., et al. Group B streptococci at delivery: high count in urine increases risk for neonatal colonization. Scand J Infect Dis 1986; 18(6): 525-31.

18. de Cueto, M., Sanchez, M.J., Sampedro, A., et al. Timing of intrapartum ampicillin and prevention of vertical transmission of group B streptococcus. Obstet Gynaecol 1998; 91(1):112-4. 19. Yancey, M.K., Schuchat, A., Brown, L.K., et al. The accuracy of late antenatal screening cultures in predicting genital group B streptococcal colonization at delivery. Obstet Gynaecol 1996; 88(5):811-5.

20. Chang, L.W., Garland, S.M., Daley, A.J., Chean R. Increasing clindamycin resistance among Australian group B streptococcus isolates. Intern Med J 2015; 45(4): 465-6.

21. The Royal Women's Hospital. Labour and Birth and Early Puerperium - Care During. [Accessed May 2017]. Available from: https://www.thewomens.org.au/health-professionals/clinicalresources/clinical-guidelines-gps/; 2015.

22. Daley, A.J., Garland, S.M. Prevention of neonatal group B streptococcal disease: Progress, challenges and dilemmas. J Paediatr Child Health 2004; 40(12):664-8.

This article is protected by copyright. All rights reserved 
23. Panda B, Iruretagoyena I, Stiller R, Panda A. Antibiotic resistance and penicillin tolerance in ano-vaginal group B streptococci. J Matern Fetal Neonatal Med, 2009; 22(2): 111-114

24. Castor ML, Whitney CG, Como-Sabetti K, Facklam RR, Ferrieri P, Bartkus JM, et al. Antibiotic resistance patterns in invasive group B streptococcal isolates. Infect Dis Obstet Gynaecol $2008 ; 727505$.

26. Prairie, B.A., Foster, T. Improving prenatal HIV screening with tailored educational interventions: an approach to guideline implementation. Qual Saf Health Care 2010; 19(6):e52.

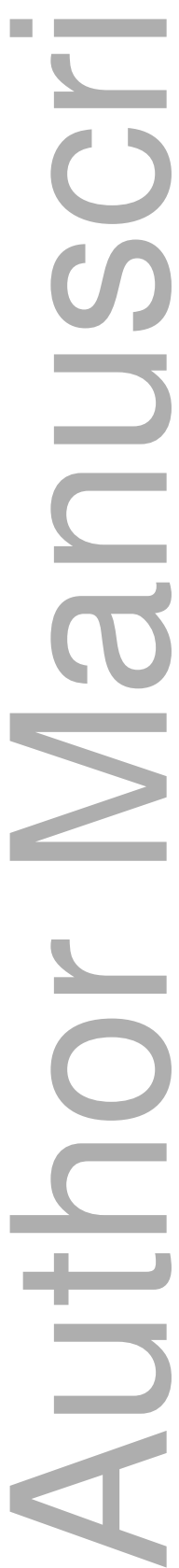




\begin{tabular}{|c|c|c|c|c|}
\hline & $\begin{array}{c}\text { Total }(\%) \\
n=741\end{array}$ & $\begin{array}{c}\text { FEB } 2016(\%) \\
n=246\end{array}$ & $\begin{array}{c}\text { FEB } 2017(\%) \\
n=249\end{array}$ & $\begin{array}{c}\text { MARCH } 2017(\%) \\
n=246\end{array}$ \\
\hline Delivery before 35 weeks & $31 / 741 \quad(4.2)$ & $9 / 246 \quad(3.7)$ & $12 / 249$ & $10 / 246 \quad(4.1)$ \\
\hline Eligible for screen & $710 / 741 \quad(95.8)$ & $237 / 246 \quad(96.3)$ & $237 / 249 \quad(95.2)$ & $236 / 246 \quad(95.9)$ \\
\hline GBS screen & $599 / 710 \quad(84.4)$ & $201 / 237 \quad(84.8)$ & $202 / 237 \quad(85.2)$ & $196 / 236 \quad(83.1)$ \\
\hline Screen 35 weeks or above & $\begin{array}{ll}561 / 599 & (93.7)\end{array}$ & $189 / 201 \quad(94.0)$ & $185 / 202 \quad(91.6)$ & $187 / 196 \quad(95.4)$ \\
\hline GBS result recorded $^{\dagger}$ & $\begin{array}{ll}558 / 561 & (99.1)\end{array}$ & $187 / 189 \quad(99.0)$ & $184 / 185 \quad(99.6)$ & $187 / 187 \quad(100)$ \\
\hline GBS positive at screen & $109 / 558 \quad(19.5)$ & $38 / 187 \quad(20.3)$ & $39 / 184 \quad(21.2)$ & $32 / 187 \quad(17.1)$ \\
\hline GBS bacteriuria ${ }^{\neq}$ & $9 / 741 \quad(1.2)$ & $3 / 246 \quad(1.2)$ & $3 / 249 \quad(1.2)$ & $3 / 246 \quad(1.2)$ \\
\hline Total GBS positive & $118 / 741 \quad(15.9)$ & $41 / 246 \quad(16.7)$ & $42 / 249$ & $35 / 246 \quad(14.2)$ \\
\hline GBS positive + labour ${ }^{\S}$ & $102 / 118 \quad(86.4)$ & $33 / 41 \quad(80)$ & $39 / 42$ & $30 / 35 \quad(86)$ \\
\hline Labour > 4 hours & $50 / 102 \quad(49.0)$ & $15 / 33 \quad(45)$ & $17 / 39$ & $\begin{array}{ll}18 / 30 \quad(60) \\
\end{array}$ \\
\hline IAP administered & $47 / 50 \quad(94)$ & $14 / 15$ & $16 / 17$ & $17 / 18$ \\
\hline To guideline & $39 / 47 \quad(83)$ & $11 / 14$ & $13 / 16$ & $15 / 17$ \\
\hline
\end{tabular}

GBS, Group B Streptococcus; IAP, Intrapartum Antibiotic Prophylaxis

${ }^{\dagger}$ Result of GBS screening available within medical records to author at time of audit

${ }^{*}$ GBS positive bacteriuria at any gestation during pregnancy

${ }^{\S}$ Vaginal delivery, excluding planned and emergency caesarean section

This article is protected by copyright. All rights reserved 


\begin{tabular}{|c|c|c|c|c|}
\hline & Total (\%) & FEB $2016(\%)$ & FEB $2017(\%)$ & MARCH 2017 (\%) \\
\hline Positive GBS + Labour & 102 & 33 & 39 & 30 \\
\hline IAP given & $94 / 102 \quad(92)$ & $30 / 33 \quad(91)$ & $37 / 39 \quad(95)$ & $27 \quad(90)$ \\
\hline Correct antibiotic & 93/94 (99) & $30 / 30 \quad(100)$ & $36 / 37 \quad(97)$ & $27 / 27 \quad(100)$ \\
\hline Correct dose & 93/94 (99) & $30 / 30 \quad(100)$ & $36 / 37 \quad(97)$ & $27 / 27 \quad(100)$ \\
\hline Overall to guideline & 93/94 (99) & $30 / 30 \quad(100)$ & $36 / 37 \quad(97)$ & $27 / 27 \quad(100)$ \\
\hline Positive GBS + Labour > 4 hours & 50 & 15 & 17 & 18 \\
\hline IAP given & $47 / 50 \quad(94)$ & $14 / 15$ & $16 / 17$ & $17 / 18$ \\
\hline Correct antibiotic & $47 / 47 \quad(100)$ & $14 / 14$ & $16 / 16$ & $17 / 17$ \\
\hline Correct dose & $47 / 47 \quad(100)$ & $14 / 14$ & $16 / 16$ & $17 / 17$ \\
\hline Adequate time ${ }^{\dagger}$ & $39 / 47 \quad(83)$ & $11 / 14$ & $13 / 16$ & $15 / 17$ \\
\hline Overall to guideline & $39 / 47 \quad(83)$ & $11 / 14$ & $13 / 16$ & $15 / 17$ \\
\hline
\end{tabular}

GBS, Group B Streptococcus; IAP, Intrapartum Antibiotic Prophylaxis

${ }^{\dagger}$ At least one dose of antibiotic, four hours prior to delivery

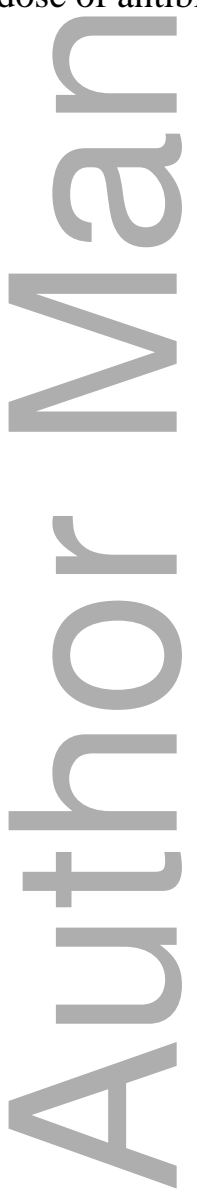




\begin{tabular}{|l|cc|c|c|c|}
\hline \multicolumn{6}{|c|}{ Table 3. Intrapartum antibiotic prophylaxis in presence of unknown GBS status and maternal risk factors ${ }^{\dagger}$. } \\
\hline & $\begin{array}{c}\text { Total (\%) } \\
\mathbf{n}=\mathbf{7 4 1}\end{array}$ & $\begin{array}{c}\text { FEB 2016 (\%) } \\
\mathbf{n}=\mathbf{2 4 6}\end{array}$ & $\begin{array}{c}\text { FEB 2017 (\%) } \\
\mathbf{n = 2 4 9}\end{array}$ & $\begin{array}{c}\text { MARCH 2017 (\%) } \\
\mathbf{n = 2 4 6}\end{array}$ \\
\hline Unknown GBS status & $113 / 741$ & $(15.2)$ & $38 / 246 \quad(15.4)$ & $35 / 249 \quad(14.1)$ & $40 / 246 \quad(16.3)$ \\
\hline At least 1 risk factor ${ }^{\dagger}$ present & $33 / 113$ & $(29.2)$ & $9 / 38 \quad(24)$ & $10 / 35 \quad(29)$ & $14 / 40 \quad(35)$ \\
\hline IAP given & $5 / 33$ & $(15)$ & $1 / 9$ & $2 / 10$ & $2 / 14$ \\
\hline
\end{tabular}

GBS, group B streptococcus; IAP, intrapartum antibiotic prophylaxis.

'Risk factors include maternal fever during labour greater than 38 degrees Celsius, rupture of membranes for greater than 18 hours, premature delivery at less than 37 weeks gestation, infant previously affected by GBS in same mother.
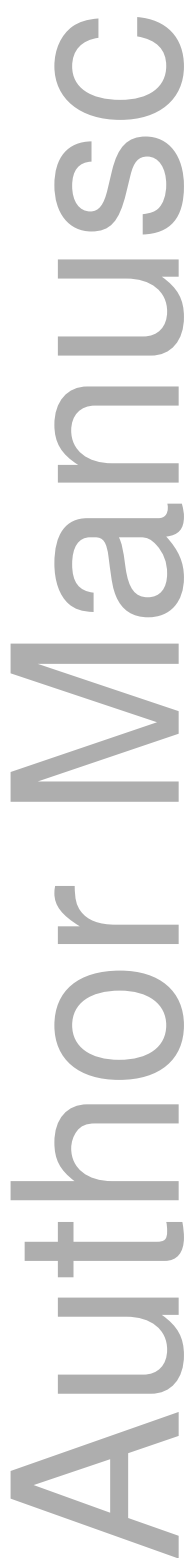
Table 4. Practical Recommendations

- Pregnant women should be screened for GBS carriage at greater than 35 weeks' gestation via combined anorectal and vaginal swab culture.

- Positive results for GBS carriage should lead to administration of IAP, with the first dose at least 4 hours prior to delivery,

- GBS remains susceptible to penicillin. For women with penicillin allergy, antibiotic sensitivity testing should be requested for their GBS swab culture isolates, as there are increasing rates of clindamycin resistance.

- Women with unknown GBS status at delivery should be monitored during labour for risk factors ${ }^{\dagger}$ for GBS, and provided with intrapartum antibiotics if risk factors are identified.

GBS, group B streptococcus; IAP, intrapartum antibiotic prophylaxis.

${ }^{\dagger}$ Risk factors include maternal fever during labour greater than 38 degrees celcius, rupture of membranes for greater than 18 hours, premature delivery at less than 37 weeks gestation, infant previously affected by GBS in same mother.

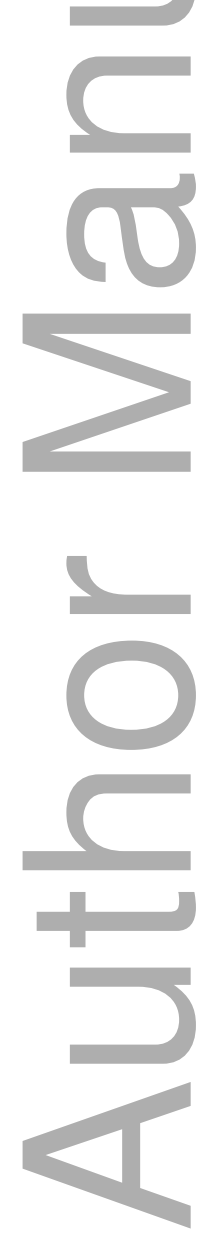




\section{Screen all women at 35-37 weeks gestation}

- Combined low vaginal plus ano-rectal swab

- Charcoal transport medium

- Document penicillin allergy on lab request for susceptibility testing

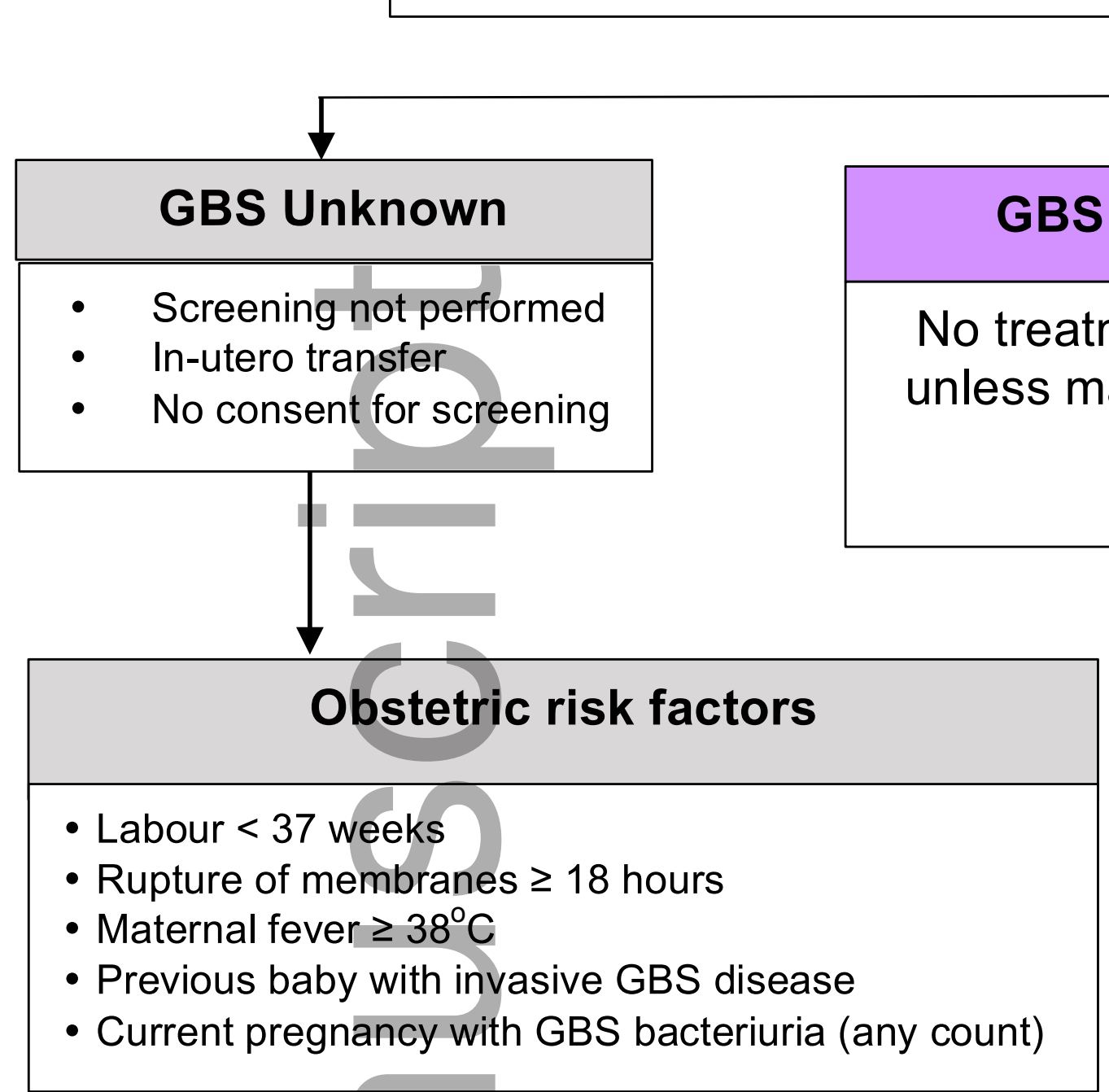

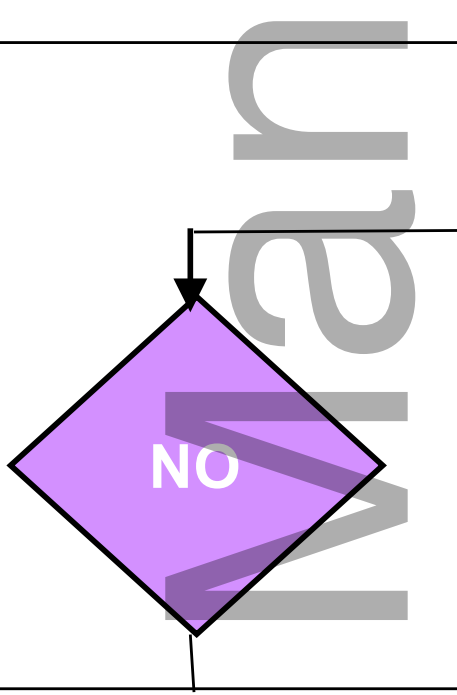

No prophylaxis

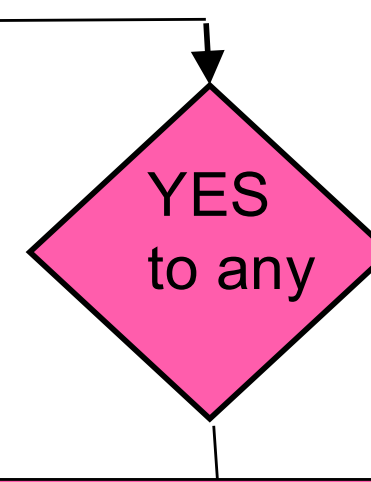

Treat as GBS positive

\section{* Penicillin Allergy}

(Excluding immediate hypersensitivity)

Cephazolin $2 \mathrm{~g}$ IV initial then $1 \mathrm{~g}$ every 8 hours until delivery

* Immediate hypersensitivity (anaphylaxis) to penicillin/cephalosporin or history of DRESS, Stevens-Johnson syndrome, toxic epidermal necrolysis, etc.

If GBS isolate sensitive to clindamycin: $600 \mathrm{mg}$ clindamycin every 8 hours until delivery

If sensitivity unknown or GBS isolate resistant to clindamycin:

Vancomycin $1 \mathrm{~g}$ IV every 12 hours until delivery This article is protected by copyright. All rights reserved

\section{Intrapartum GBS prophylaxis}

- Initial dose of $3 \mathrm{~g}$ IV benzylpenicillin* from the onset of labour or from the time of ruptured membranes, followed by:

- $1.8 \mathrm{~g}$ IV benzylpenicillin every 4 hours until delivery

\section{Suspected or overt intrauterine sepsis}

Fever $\geq 38^{\circ} \mathrm{C}$

Tachycardia

Other signs suggestive of chorioamnionitis:

- Purulent/offensive liquor

- Uterine tenderness

- Fetal tachycardia

\section{Investigations}

\section{Blood cultures}

FBE / CRP

Endocervical swab

MSU / CSU

Commence broad spectrum antibiotics 


\section{University Library}

\section{- M M N E R VA A gateway to Melbourne's research publications}

Minerva Access is the Institutional Repository of The University of Melbourne

Author/s:

Moorhead, R;Daley, AJ;Lee, L-Y;Gorelik, A;Garland, SM

Title:

Compliance with screening for and recommended management of maternal group B streptococcus carriage in pregnancy

Date:

2019-12-01

Citation:

Moorhead, R., Daley, A. J., Lee, L. -Y., Gorelik, A. \& Garland, S. M. (2019). Compliance with screening for and recommended management of maternal group B streptococcus carriage in pregnancy. AUSTRALIAN \& NEW ZEALAND JOURNAL OF OBSTETRICS \& GYNAECOLOGY, 59 (6), pp.837-842. https://doi.org/10.1111/ajo.12977.

Persistent Link:

http://hdl.handle.net/11343/285710 